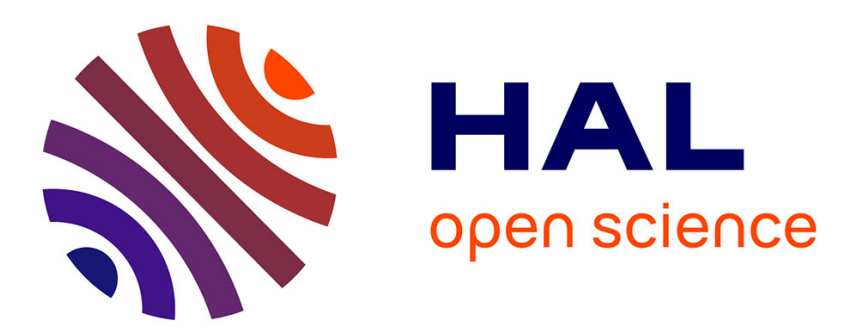

\title{
Identification of Nanomolar Lectin Ligands by a Glycodendrimer Microarray
}

Eugenie Laigre, Claire Tiertant, David Goyard, Olivier Renaudet

\section{To cite this version:}

Eugenie Laigre, Claire Tiertant, David Goyard, Olivier Renaudet. Identification of Nanomolar Lectin Ligands by a Glycodendrimer Microarray. ACS Omega, 2018, 3 (10), pp.14013-14020. 10.1021/acsomega.8b01526 . hal-02087822

\section{HAL Id: hal-02087822 \\ https://hal.univ-grenoble-alpes.fr/hal-02087822}

Submitted on 2 Apr 2019

HAL is a multi-disciplinary open access archive for the deposit and dissemination of scientific research documents, whether they are published or not. The documents may come from teaching and research institutions in France or abroad, or from public or private research centers.
L'archive ouverte pluridisciplinaire HAL, est destinée au dépôt et à la diffusion de documents scientifiques de niveau recherche, publiés ou non, émanant des établissements d'enseignement et de recherche français ou étrangers, des laboratoires publics ou privés. 


\title{
Identification of Nanomolar Lectin Ligands by a Glycodendrimer Microarray
}

\author{
Eugénie Laigre, Claire Tiertant, David Goyard,* and Olivier Renaudet*º \\ Univ. Grenoble Alpes, CNRS, DCM UMR 5250, F-38000 Grenoble, France \\ Supporting Information
}

ABSTRACT: Carbohydrate-protein interactions play key roles in a wide variety of biological processes. These interactions are usually weak, with dissociation constants in the low millimolar to high micromolar range. Nature uses multivalency to reach high avidities via the glycoside cluster effect. Capitalizing on this effect, numerous synthetic multivalent glycoconjugates have been described and used as ligands for carbohydrate-binding proteins. However, valency is only one of the several parameters governing the binding mechanisms that are different for every biological receptor, making it almost impossible to predict. In this context, ligand optimization requires the screening of a large number of structures with different valencies, rigidities/ flexibilities, and architectures. In this article, we describe a screening platform based on a glycodendrimer array and its use to determine the key parameters for high-affinity ligands of lectin. Several glycoclusters and glycodendrimers displaying varying numbers of $\alpha$ - $N$-acetylgalactosamine residues were covalently attached on glass slides, and their bindings were studied with the fluorophore-functionalized Helix pomatia agglutinin (HPA) used as a lectin model. This technique requires minimal quantities of glycoconjugate compared to those for other techniques and affords useful information on the binding strength. Building of the glycodendrimer array and quantification of the interactions with HPA are described.

\section{INTRODUCTION}

Multivalent glycoarchitectures have progressively emerged as relevant molecular systems for diagnostic and therapeutic applications. ${ }^{1-3}$ Strong interaction with carbohydrate-binding proteins (i.e., lectins and antibodies) by means of the glycoside cluster effect ${ }^{4-6}$ is the prerequisite to the development of efficient tools, such as diagnostic probes, antiadhesives, and antitumoral therapeutics or drug-delivery systems. However, despite major progresses in the deciphering of binding mechanisms, the design of high-affinity ligands remains almost impossible to predict because each biological receptor specifically responds to multivalent ligands according to its own structural parameters. ${ }^{7,8}$ For this reason, the development of active ligands often requires time-consuming synthesis of libraries of structures with diverse geometries and valencies and in a sufficient quantity $(\sim 10 \mathrm{mg})$ to allow reliable biological investigations.

Microarray technology has clearly demonstrated its efficacy to probe interactions between carbohydrates and biological targets $^{9-17}$ (i.e., proteins, pathogens, or cells) because the microarray format requires lower quantities of both ligand and protein than those required for standard experiments such as isothermal titration calorimetry (ITC) or enzyme-linked immunosorbent assay-type assays, ${ }^{18,19}$ is easy to set up, and is reusable. ${ }^{20}$ If covalent immobilization of carbohydrates on surfaces allows multivalent presentation, the resulting two- dimensional disposition only partially reflects their natural display, which strongly limits the access of reliable information to design potent multivalent ligands. In addition, even though surface density can be tuned easily, intermolecular chelation of lectins with monovalent ligands may occur, thus leading to an uninterpretable surface cluster effect. More recently, glycocluster-based microarrays have been developed to both overcome these limitations and improve sensitivity of detection. The controlled presentation of sugars in a welldefined three-dimensional arrangement and at low surface density indeed gives access to the direct analysis and binding properties of the immobilized compound. For example, Pieters et al. have immobilized 1- to 8-valent structures covalently onto porous aluminum oxide chips to monitor multivalency effects in real time with fluorescent lectins. ${ }^{21}$ In another study, the same group has drawn binding profiles for a series of lectins, which has highlighted both specific recognition and distinct binding patterns. ${ }^{22}$ The groups of Morvan and Chevolot have used the noncovalent DNA-directed immobilization method for immobilizing glycocluster-DNA conjugates on DNA microarrays by double-helix formation. ${ }^{23,24}$ Fluorescence endpoint detection was used to screen these

Received: July 3, 2018

Accepted: September 7, 2018

Published: October 25, 2018 
Scheme 1. Synthesis of Tetravalent Glycoclusters ${ }^{a}$

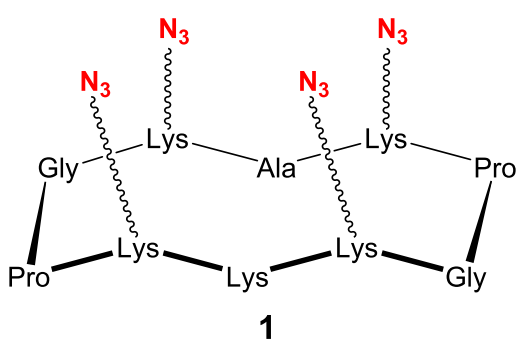<smiles>C[C@H](NC(=O)C(CCCCNC(=O)[C@H](CCCCN)NC(=O)CN)NC(=O)[C@H](CCCCN)NC(=O)CN)C(=O)N[C@@H](CCCCN)C(N)=O</smiles>

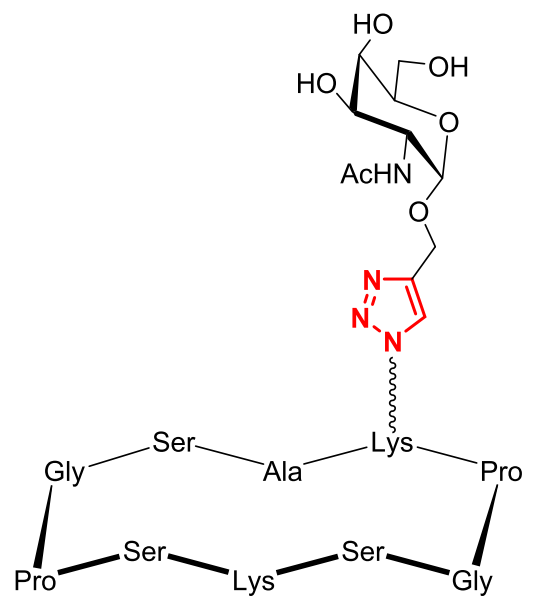

5
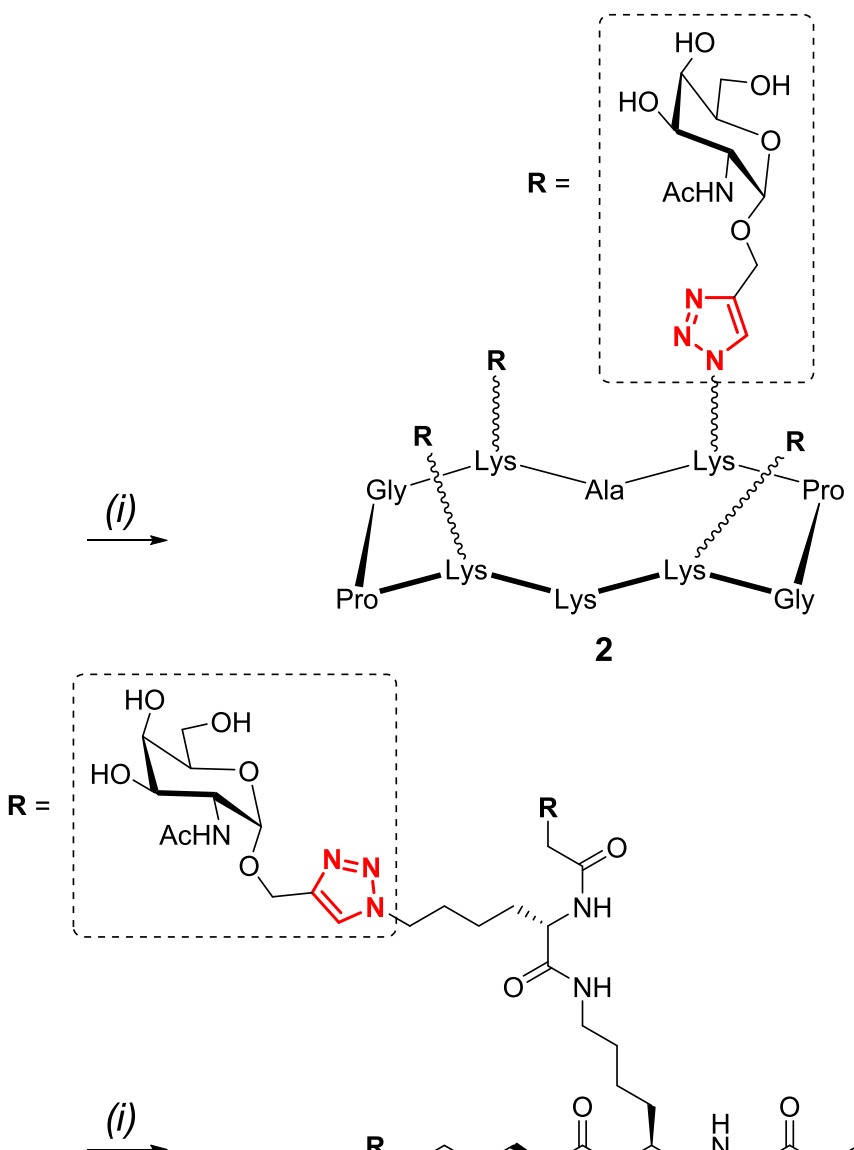

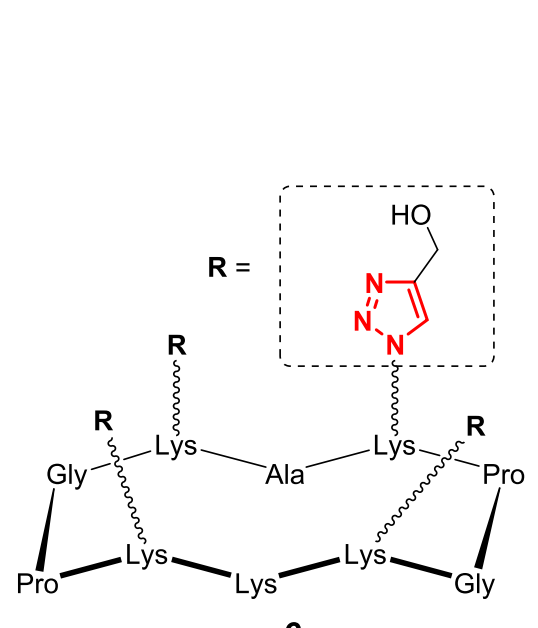

6<smiles>[R]CCCC[C@H](NC(=O)C[R])C(=O)N[C@@H](CCCCNC(=O)[C@H](C)CCCCC)C(=O)N[C@@H](C)C(=O)N[C@@H](CCCCN)C(N)=O</smiles>

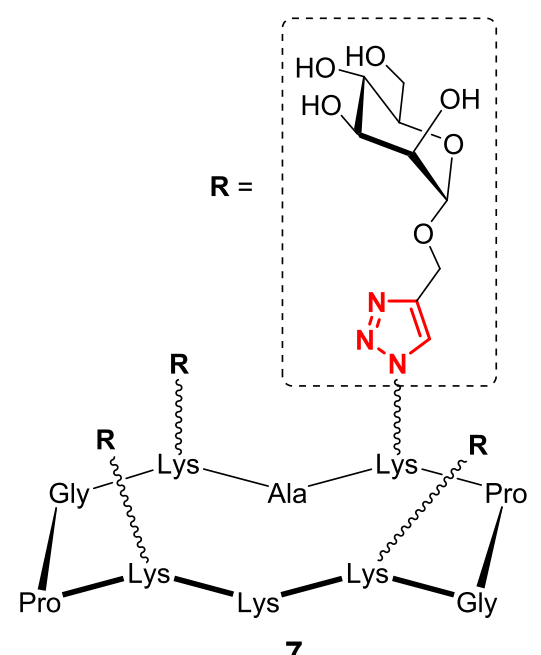

${ }^{a}$ Reagents and conditions: (i) propargyl 2-deoxy-2-acetamido- $\alpha$-D-galactopyranoside, $\mathrm{CuSO}_{4} \cdot 5 \mathrm{H}_{2} \mathrm{O}$, tris (3-hydroxypropyltriazolylmethyl)amine (THPTA), sodium ascorbate, dimethylformamide (DMF)/phosphate-buffered saline (PBS) (1:3, pH 7.5), room temperature (rt), 1 h. All amino acids have the L-configuration.

ligands toward lectins. After studying the impact of the cluster density, they have been able to identify nanomolar inhibitors for the lectin LecA from Pseudomonas aeruginosa. ${ }^{25}$ All of these studies clearly demonstrated that the spatial arrangement of multivalent structures on surfaces favors stronger interactions with lectins than with monovalent ligands. However, these experiments allowed discrimination of ligands with significant differences in valency, thus leading to predictable data in the majority of cases. On the contrary, systematic evaluation of ligands with close structural features in terms of rigidity/ 
Scheme 2. Synthesis of Hexadecavalent Glycodendrimers ${ }^{a}$
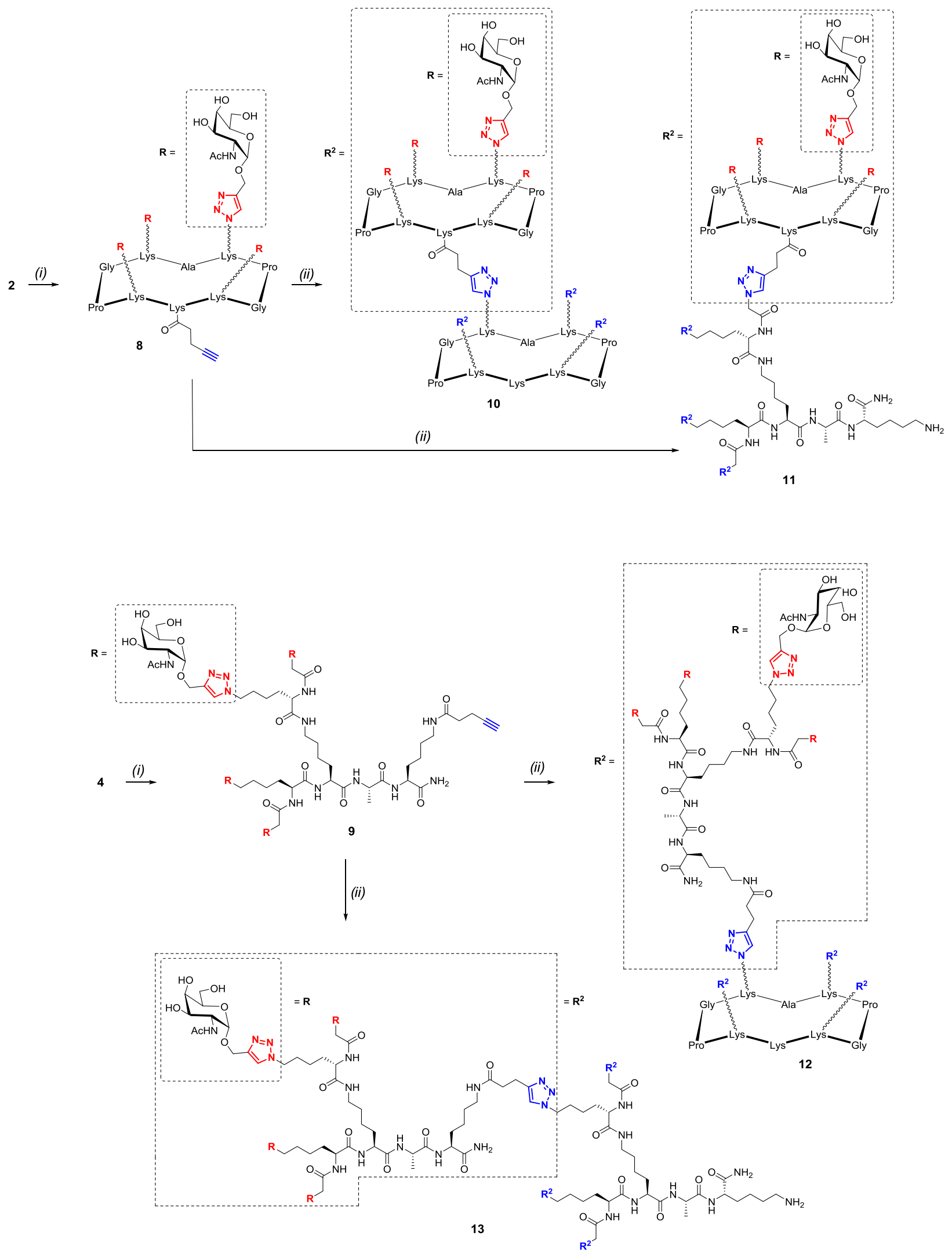

${ }^{a}$ Reagents and conditions: (i) 2,5-dioxopyrrolidin-1-yl pent-4-ynoate, diisopropylethylamine, DMF, rt, 30 min. (ii) 1 or $2, \mathrm{CuSO}_{4} \cdot 5 \mathrm{H}_{2} \mathrm{O}, \mathrm{THPTA}$, sodium ascorbate, DMF/PBS (1:3, pH 7.5), rt, $1 \mathrm{~h}$. 
Scheme 3. Glycoconjugate Immobilization and Binding and Competition Assays

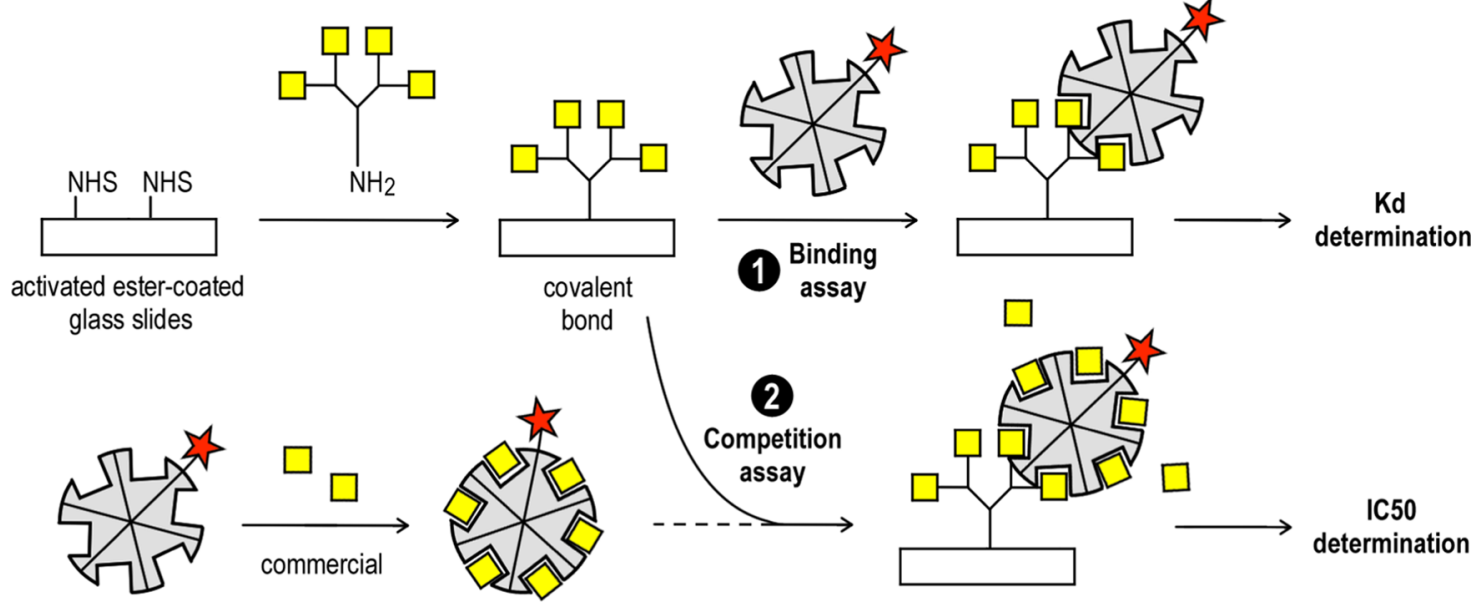

flexibility, size, and valency that are key parameters to identify potent inhibitors has only rarely been described so far. ${ }^{26}$ In this study, we report the immobilization and screening of a series of $N$-acetyl- $\alpha$-D-galactosamine-functionalized ( $\alpha$ GalNAc) tetraand hexadecavalent glycodendrimers on microarray slides. Using this screening platform, different binding assays were performed, to quantify their affinity toward the $\alpha$ GalNAcspecific Helix pomatia agglutinin (HPA) lectin. HPA is a hexameric lectin produced by a roman snail. This lectin displays two trimers constituted of monomers linked by disulfide bridges. This $\beta$-sandwich fold leads to two domains distant of $100 \AA$, each displaying three carbohydrate recognition domains located between two adjacent monomer strands, with $20 \AA$ distance between two neighboring binding sites. $^{27}$

\section{RESULTS AND DISCUSSION}

In a preliminary report, our group has shown that covalent immobilization of glycoclusters on glass slides using both direct and indirect oxime ligation strategies affords surfaces displaying well-defined structures capable of interacting selectively with fluorescent lectins. ${ }^{28}$ In particular, we have reported that a tetravalent $\alpha$ GalNAc-cluster showed promising but moderate interaction with HPA. To improve its recognition potency, several elements have to be tuned in the structure. We first decided to increase the valency to 16 copies onto scaffolds with variable flexibilities and shapes. Alternate combination of cyclopeptides and/or polylysine dendrons was indeed proved to be successful to identify nanomolar inhibitors of the bacterial lectin LecB from $P$. aeruginosa. $^{29}$ Similar structures have thus been synthesized following a strategy based on copper-catalyzed azide-alkyne cycloaddition (CuAAC)..$^{30,31}$

Synthesis of Multivalent Glycoconjugates. First, tetravalent glycoclusters 2 and $\mathbf{4}$ were prepared by CuAAC conjugation of propargyl 2-deoxy-2-acetamido- $\alpha$-D-galactopyranoside $^{32}$ on azido-functionalized cyclodecapeptide $\mathbf{1}$ and polylysine dendron 3 (Scheme 1$){ }^{30}$ Monofunctionalized compound 5 was also prepared, as a monomeric reference, and clusters 6 and 7 displaying hydroxymethyl and $\alpha$ mannoside residues, respectively, were chosen to serve as negative controls in the binding studies.

Next, hexadecavalent compounds were built in a convergent manner. Clusters 2 and $\mathbf{4}$ were further functionalized on their remaining free lysine residue with an $N$-hydroxysuccinimide (NHS)-activated pentynoic acid linker ${ }^{33}$ to afford intermediates $\mathbf{8}$ and $\mathbf{9}$. A second CuAAC ligation with scaffolds $\mathbf{1}$ and $\mathbf{2}$ yielded glycodendrimers 10-13 displaying 16 copies of $\alpha$ GalNAc (Scheme 2).

Glycoarray Fabrication. To ensure a reproducible and controlled display of the multivalent glycoconjugates, covalent immobilization was chosen, exploiting the free amino group on their lysine side chain and NHS-activated glass slides to obtain an amide linkage. Compounds were spotted in triplicate using a piezoelectric microspotter at various concentrations in buffered solutions (PBS $1 \times$ with $5 \%$ glycerol). The volume of each drop was monitored by spotter software to obtain final spots with a controlled diameter of $200 \mu \mathrm{m}$. The experiments have been performed while monitoring the humidity to prevent evaporation. With this platform in hand, qualitative binding assays as well as $K_{\mathrm{d}}$ and $\mathrm{IC}_{50}$ determination could be performed (Scheme 3).

Binding Assays. To facilitate the binding assays, the functionalized glass slide was inserted into a rigid mask with silicon separators, creating 16 isolated wells and allowing us to evaluate 14 different experimental conditions in parallel. Lectin solutions (PBS $1 \times \mathrm{pH} 7.5$ with $0.1 \%$ BSA) ranging from 7.5 $\mu \mathrm{M}$ to $0.15 \mathrm{nM}$ were poured in the mask wells and incubated for $1 \mathrm{~h}$. After washing with PBS and drying with argon, the slide was scanned and the fluorescence intensities were quantified using a fluorescent scanner (Figure 1).

First, the absence of signal for tetravalent compounds $\mathbf{6}$ and 7 , functionalized with hydroxymethyl and $\alpha$-mannoside, respectively, confirms that nonspecific interactions either with the surface or with a sugar other than $\alpha$ GalNAc are not observed. This assay also showed a significant difference between glycoclusters 2 and 4, suggesting that the interaction with the latter, based on the lysine dendron, is much stronger. The data obtained for hexadecavalent glycodendrimers also show a more favorable binding when this lysine dendron is used whether as the central (higher intensities for $\mathbf{1 1}$ and $\mathbf{1 3}$ compared to those for $\mathbf{1 0}$ and $\mathbf{1 2}$, respectively) or peripheral (higher intensities for $\mathbf{1 2}$ and $\mathbf{1 3}$ compared to those for $\mathbf{1 0}$ and 11, respectively) scaffold. Finally, on correcting the intensity values with regard to the compounds' valencies (Figure 1C), compound 13 shows the highest relative potency per sugar residue over other hexadecavalent structures. It should also be mentioned that when glycoclusters are diluted with com- 

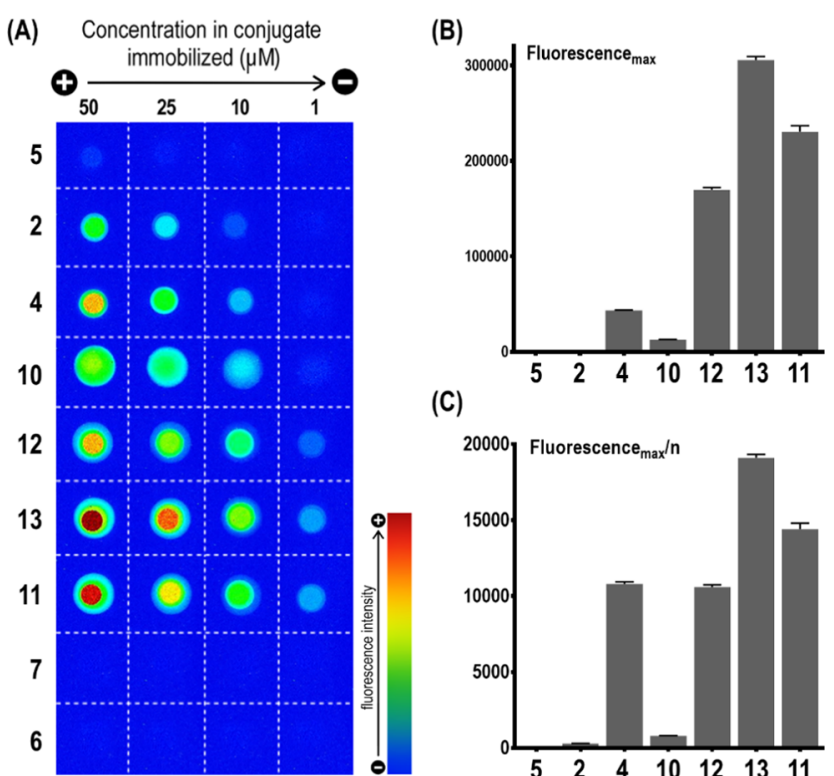

(C)

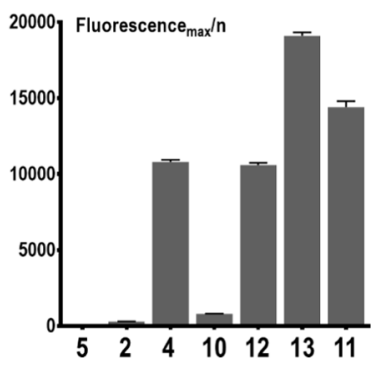

Figure 1. Fluorescence intensity evaluation for the interaction of multivalent glycoconjugates with HPA: (A) rainbow picture displaying fluorescence intensity (HPA: $1.9 \mathrm{nM}, \lambda_{\text {ex }}=635 \mathrm{~nm}$ ); (B) comparison of the maximum of fluorescence (HPA: $7.5 \mathrm{nM}$; immobilization concentration of ligand: $40 \mu \mathrm{M}$ ); and (C) comparison of the maximum of fluorescence normalized per monosaccharide unit (HPA: $7.5 \mathrm{nM}$; immobilization concentration of ligand: $40 \mu \mathrm{M}$ ).

pounds devoid of GalNAc instead of free buffer, no difference of interaction is observed. This result is in good agreement with previous observations and suggests that glycoclusters are immobilized in a homogenous manner on the surface. ${ }^{34}$

Measurement of $K_{d}$ Values. The strength of the interaction and the influence of relative surface densities of glycoconjugates were assessed in the measurement of dissociation constants $\left(K_{d}\right)$ values. ${ }^{24,35,36}$ To this end, compounds were spotted at eight different concentrations, ranging from $0.3 \mathrm{nM}$ to $40 \mu \mathrm{M}$. Binding isotherms were obtained for each set of concentrations by increasing the concentration of lectin, and $K_{\mathrm{d}}$ values were obtained by linear regression (Figure 2). ${ }^{37}$ To have a progressive isotherm reaching a maximum plateau region, lectin has to be introduced in excess relative to the glycocluster. In the case of the monovalent compound $\mathbf{5}$ and the tetravalent compounds 2 and 4, this plateau could not be reached and
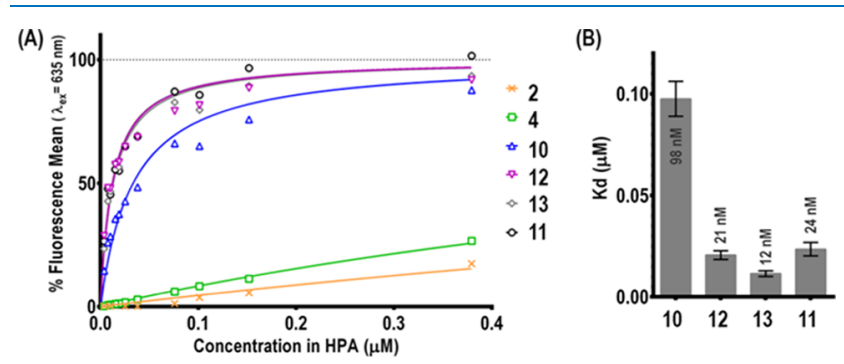

Figure 2. Determination of dissociation constants: (A) binding curves for the tetra- and hexadecavalent glycoconjugates (immobilization concentration: $10 \mu \mathrm{M}$ ); (B) comparison of the dissociation constants for the hexadecavalent structures (mean of the $K_{\mathrm{d}}$ determined for a range of immobilization concentration of $40-0.3 \mu \mathrm{M}$; see the Supporting Information). therefore $K_{\mathrm{d}}$ 's could only be precisely calculated for hexadecavalent molecules 10-13.

The dissociation constant is a thermodynamic parameter that should not be dependent on the experimental conditions (as opposed to $\mathrm{IC}_{50}$ ). However, some authors have reported that above a given surface density a receptor can interact with epitopes from two neighboring glycoconjugates, leading to a surface cluster effect and a decrease of $K_{\mathrm{d}} \cdot{ }^{38,39}$ In our case, this phenomenon was observed at spotting concentrations above $10 \mu \mathrm{M}$ (see the Supporting Information). Therefore, only $K_{\mathrm{d}}$ 's calculated at lower concentrations were considered.

The values obtained confirmed what was observed in the qualitative binding assays. Compound 13 composed of two layers of lysine dendron showed the best affinity with a $K_{\mathrm{d}}$ of $12 \mathrm{nM}$. Compounds 11 and 12 alternating the two scaffolds gave very similar results with $K_{\mathrm{d}}$ values of 24 and $21 \mathrm{nM}$, respectively. However, compound $\mathbf{1 0}$ seemed to be a weaker ligand with a $K_{\mathrm{d}}$ of $98 \mathrm{nM}$. Although these four compounds have the same valency, a significant difference of affinity of almost 1 order of magnitude could be evidenced with our assay.

Measurement of $\mathrm{IC}_{50}$ Values. To determine $\mathrm{IC}_{50}$ values, assays were performed using GalNAc as a competitor. Glycoconjugates were immobilized at $10 \mu \mathrm{M}$ to avoid the surface cluster effect that could affect the outcome of the experiment. Solutions of HPA $(7.5 \mathrm{nM})$ and GalNAc at various concentrations, from $50 \mathrm{mM}$ to $1 \mu \mathrm{M}$, were preincubated for $1 \mathrm{~h}$. These solutions were then incubated for $1 \mathrm{~h}$ in the slide's wells functionalized with glycodendrimers. The resulting $\mathrm{IC}_{50}$ values (Figure 3 ) are the concentrations in
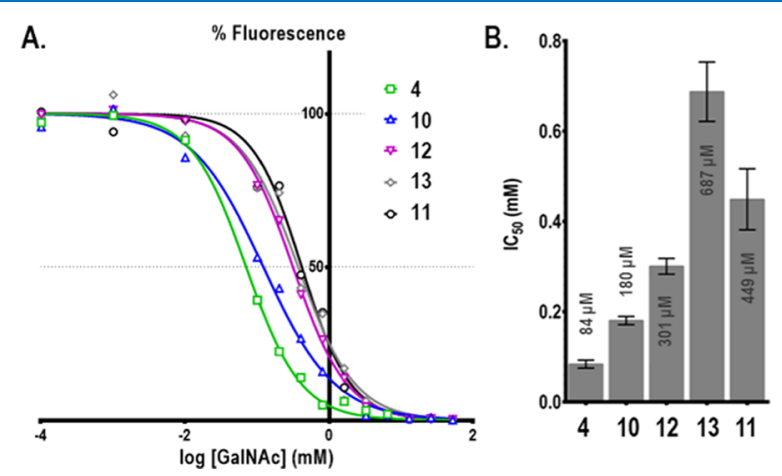

Figure 3. $\mathrm{IC}_{50}$ determination by competition with GalNAc incubated with HPA at $7.5 \mathrm{nM}$ (immobilization concentration: $10 \mu \mathrm{M}$ ): (A) inhibition curves; (B) $\mathrm{IC}_{50}$ values determined for the competitor.

the competitor required to inhibit half of the HPAglycoconjugate interaction. At this immobilization concentration $(10 \mu \mathrm{M}), \mathrm{IC}_{50}$ values could only be obtained for the hexadecavalent compounds and tetravalent molecule 4 . When comparing the affinities of hexavalent dendrimers, the same relative potencies were observed as with $K_{d}$ measurements. Compound 10 with an $\mathrm{IC}_{50}$ of $180 \mu \mathrm{M}$ showed the weakest binding as opposed to compound $13\left(\mathrm{IC}_{50}=687 \mu \mathrm{M}\right)$. Once again molecules 11 and $\mathbf{1 2}$ showed no significant difference with intermediate values of 449 and $301 \mu \mathrm{M}$, respectively.

Enzyme-Linked Lectin Assay (ELLA). To confirm the reliability of the screening method, enzyme-linked lectin assays (ELLA) have been performed (Figure 4). In contrast to the $\mathrm{IC}_{50}$ values evaluated by the microarray, in the ELLA experiment, the half-inhibition concentration was determined 
(A)
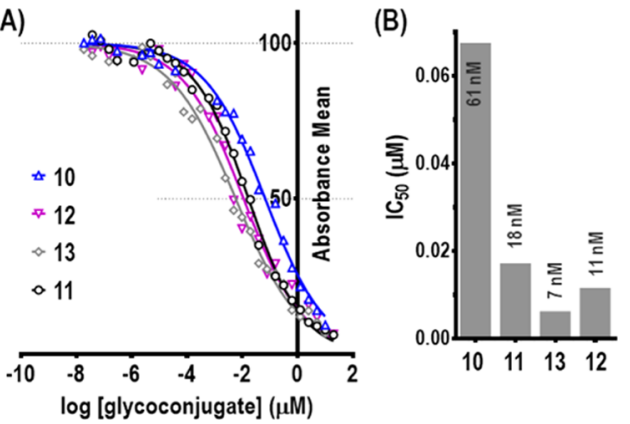

Figure 4. ELLA experiments: (A) inhibition curves; (B) $\mathrm{IC}_{50}$ values determined for the hexadecavalent conjugates.

for the glycodendrimers with an $\alpha$ GalNAc-functionalized polymer used as the immobilized reference ligand. The lowest value was determined for compound $\mathbf{1 3}$ with an $\mathrm{IC}_{50}$ of $7 \mathrm{nM}$ and the highest one for 10 with $61 \mathrm{nM}$ that corresponds to a difference of approximately 1 order of magnitude. Compounds 11 and 12 display similar $\mathrm{IC}_{50}$ values with, respectively, 18 and $11 \mathrm{nM}$. These results are in excellent agreement with the trend previously observed by microarray evaluations.

\section{CONCLUSIONS}

In this study, we demonstrate that glycodendrimer arrays allow rapid screening of multivalent glycostructures toward lectin. By grafting multivalent architectures in a controlled, covalent manner on a glass slide, we have evaluated the binding of $\alpha$ GalNAc-ligands with the lectin HPA both qualitatively, with a simple binding assay, and quantitatively, allowing for $K_{\mathrm{d}}$ and $\mathrm{IC}_{50}$ values. All of the collected data have shown consistent results, thus confirming the reliability of this method (Table 1). Compared with other techniques such as ITC, surface plasmon resonance, or ELLA inhibition assays, the microarray format requires very low quantities of ligands, is versatile and easy to handle, and can be used to screen a large library of ligands in parallel. In addition, this approach offers the advantage to allow interaction studies with no risk of aggregation that often occurs with multivalent compounds. Together with the previous "indirect method" that allows us to synthesize glycostructures on surfaces using successive conjugation steps, ${ }^{28}$ we expect to develop an expedient method to assemble glycodendrimers on surfaces with a larger quantity and diversity of platforms and sugar units. The resulting arrays would represent ideal tools to discover highaffinity ligands for relevant bacterial lectins or antibodies for both therapeutic and diagnostic applications.

\section{EXPERIMENTAL SECTION}

General Methods. All chemical reagents were purchased from Aldrich (Saint Quentin Fallavier, France) or Acros (Noisy-Le-Grand, France) and were used without further purification. All protected amino acids and Fmoc-Gly-Sasrin resin were obtained from Advanced ChemTech Europe (Brussels, Belgium), BachemBiochimie SARL (Voisins-LesBretonneux, France) and France Biochem S.A. (Meudon, France). For peptides and glycopeptides, analytical reverse phase high-performance liquid chromatography (RP-HPLC) was performed on a Waters alliance 2695 separation module, equipped with a Waters $2489 \mathrm{UV} /$ visible detector. Analyses were carried out at $1.23 \mathrm{~mL} / \mathrm{min}$ (Interchim UPTISPHERE XSERIE, $\mathrm{C}_{18}, 5 \mu \mathrm{m}, 125 \times 3.0 \mathrm{~mm}^{2}$ ) with UV monitoring at 214 and $250 \mathrm{~nm}$ using a linear $\mathrm{A}-\mathrm{B}$ gradient (buffer $\mathrm{A}: 0.09 \%$ $\mathrm{CF}_{3} \mathrm{CO}_{2} \mathrm{H}$ in water; buffer $\mathrm{B}$ : $0.09 \% \mathrm{CF}_{3} \mathrm{CO}_{2} \mathrm{H}$ in $90 \%$ acetonitrile). Preparative HPLC was performed on Waters equipment consisting of a Waters 600 controller and a Waters 2487 Dual Absorbance Detector. Purifications were carried out at $22.0 \mathrm{~mL} / \mathrm{min}\left(\mathrm{VP} 250 \times 21 \mathrm{~mm}^{2}\right.$ nucleosil $\left.100-7 \mathrm{C}_{18}\right)$ with UV monitoring at 214 and $250 \mathrm{~nm}$ using a linear $\mathrm{A}-\mathrm{B}$ gradient. Progress of reactions was monitored by thin layer chromatography using silica gel 60 F254-precoated plates (Merck). Spots were visualized by charring with $10 \% \mathrm{H}_{2} \mathrm{SO}_{4}$ in EtOH. Silica gel 60 (0.063-0.2 mm or 70-230 mesh, Merck) was used for column chromatography. ${ }^{1} \mathrm{H}$ and ${ }^{13} \mathrm{C}$ NMR spectra were recorded on a BrukerAvance III $500 \mathrm{MHz}$ spectrometer, and chemical shifts $(\delta)$ were reported in parts per million ( $\mathrm{ppm})$. Spectra were referenced to the residual proton solvent peaks relative to the signal of $\mathrm{D}_{2} \mathrm{O}(4.79 \mathrm{ppm}$ for ${ }^{1} \mathrm{H}$ ). ESI mass spectra of peptides and glycopeptides were measured on an Esquire 3000 spectrometer from Bruker or on an Acquity UPLC/MS system from Waters equipped with a SQ2 detector. high-resolution mass spectrometry analyses were performed on a Waters Xevo G2-S QTof at mass spectrometry facility, PCN-ICMG, Grenoble.

General Procedures. General Procedure A for CopperCatalyzed Azide Alkyne Cycloaddition (CuAAC). A solution of $\mathrm{CuSO}_{4} \cdot 5 \mathrm{H}_{2} \mathrm{O}$ (0.1 equiv per alkyne), THPTA (0.2 equiv per alkyne), and sodium ascorbate (1 equiv per alkyne) in PBS buffer $(400 \mu \mathrm{L}, \mathrm{pH} 7.5)$ was added to a solution of azidated scaffold (1 equiv) and propargyl 2-deoxy-2-acetamido- $\alpha$-Dgalactopyranoside (6 equiv) or propargylated glycocluster (4.4 equiv) in $400 \mu \mathrm{L}$ of a $1: 1$ mixture of DMF/PBS buffer ( $\mathrm{pH}$ 7.5). The mixture was degassed under argon and stirred at room temperature for $1 \mathrm{~h}$, after which ultra performance liquid chromatography (UPLC) analysis showed complete coupling. Chelex resin was added to the reaction mixture that was stirred for an additional $30 \mathrm{~min}$ and purified by semipreparative RP-

Table 1. Compilation of the Data Obtained by Microarray and ELLA

\begin{tabular}{|c|c|c|c|c|c|c|}
\hline conjugate & valency & $K_{\mathrm{d}, \text { microarray,iso } \mathrm{T}}(\mathrm{nM})$ & $\operatorname{SEM}\left(K_{\mathrm{d}, \text { microarray,iso } \mathrm{T}}\right)(\mathrm{nM})$ & $\mathrm{IC}_{50, \text { microarray }}(\mu \mathrm{M})^{a}$ & $\operatorname{SEM}\left(\mathrm{IC}_{50, \text { microarray }}\right)(\mu \mathrm{M})^{a}$ & $\mathrm{IC}_{50, \mathrm{ELLA}}(\mathrm{nM})^{b}$ \\
\hline 5 & 1 & na & na & na & na & na \\
\hline 2 & 4 & na & na & na & na & na \\
\hline 4 & 4 & na & na & 84 & 9 & na \\
\hline 10 & 16 & 98 & 9 & 180 & 9 & 61 \\
\hline 12 & 16 & 24 & 3 & 301 & 17 & 18 \\
\hline 13 & 16 & 12 & 1 & 687 & 69 & 7 \\
\hline 11 & 16 & 21 & 2 & 449 & 68 & 11 \\
\hline
\end{tabular}

${ }^{a}$ Determined for the competitor and for an immobilization concentration of $10 \mu \mathrm{M}$ for the ligand. ${ }^{b}$ Determined for the conjugate. 
HPLC (5-40\% solvent B in $15 \mathrm{~min}$ ) to afford the desired compound as a white fluffy solid after lyophilization.

General Procedure B for Coupling of NHS-Activated Pentynoic Acid. To a solution of glycocluster (1 equiv) in dry DMF $(200 \mu \mathrm{L})$ were added diisopropylethylamine (3 equiv) and $N$-succinimidyl pentynoate (1.5 equiv). The mixture was stirred at room temperature (rt) for $1 \mathrm{~h}$, after which UPLC analysis showed complete conversion. $\mathrm{H}_{2} \mathrm{O}(3 \mathrm{~mL})$ was then added to the mixture, which was purified by semipreparative RP-HPLC (5-40\% solvent B in $15 \mathrm{~min}$ ) to afford the desired compound as a white fluffy solid after lyophilization.

Microarray Fabrication. Samples were dissolved in ultrapure $\mathrm{H}_{2} \mathrm{O}$ to prepare stock solutions $(1 \mathrm{mM})$ and then diluted in PBS $1 \times(140 \mathrm{mM} \mathrm{NaCl}, 3 \mathrm{mM} \mathrm{KCl}, 10 \mathrm{mM}$ $\mathrm{Na}_{2} \mathrm{HPO}_{4}, 2 \mathrm{mM} \mathrm{KH} \mathrm{PO}_{4}, \mathrm{pH} 8.5$ ) containing 5\% glycerol. Glycerol was used to prevent evaporation during spotting steps. The solutions of glycoconjugates $(20 \mu \mathrm{L}, 100 \mu \mathrm{M}$ to $0.03 \mu \mathrm{M})$ were transferred in a 384-well plate and then spotted in triplicate using a piezoelectric microspotter (sciFLEXARRAYER S3, Scienion AG, Germany) on NHS-coated glass slides (Nexterion, Slide H, Schott). During the printing step, the humidity was monitored by a humidifier in the spotter enclosure (75\% humidity) to prevent the evaporation of the spots. Each spot position was fixed with the software of the spotter. A distance of 480-500 $\mu \mathrm{m}$ between the centers of adjacent spots was imposed, and each probe was spotted in triplicate (6-7 drops, $400 \mathrm{pL} / \mathrm{drop}$, spot size $200 \mu \mathrm{m})$. After completion of the printing step, glass slides were incubated in a humidity chamber (70\% humidity imposed by saturated $\mathrm{NaCl}$ ) for 17-20 h. The slides were dipped into the blocking solution (PBS $1 \times, 100 \mathrm{mM}$ boric acid, $25 \mathrm{mM}$ ethanolamine, $0.01 \%$ Tween 20, $\mathrm{pH} \mathrm{8.5)} \mathrm{to} \mathrm{deactivate} \mathrm{unreacted} \mathrm{NHS-functions} \mathrm{and}$ agitated for $1 \mathrm{~h}$ at $37{ }^{\circ} \mathrm{C}$. Slides were washed in PBS $1 \times$ containing $0.1 \%$ Tween $20(3 \times, 3 \mathrm{~min})$ and then were rinsed in PBS $1 \times(3 \times, 3 \mathrm{~min})$ and in ultrapure $\mathrm{H}_{2} \mathrm{O}$ to remove salt. Slides were dried with argon and directly used for interaction or competition assays. Slides can also be conserved in $\mathrm{H}_{2} \mathrm{O}$ in a fridge for 1 month without observing any alteration.

Binding Studies. Interaction Assay Procedure. Printed slides were disposed into 16-well masks. Fields containing immobilized glycoconjugates were probed with Alexa Fluor 647-labeled $H$. pomatia agglutinin lectin (HPA) $(80 \mu \mathrm{L}, 2 \mu \mathrm{g} /$ $\mathrm{mL}$ to $2 \mathrm{ng} / \mathrm{mL}$ ) in PBS $1 \times$ containing $0.1 \%$ BSA for $1 \mathrm{~h}$ at 37 ${ }^{\circ} \mathrm{C}$. Bovine serum albumin was added to prevent nonspecific interaction of lectin with the slide and minimize the background signal. Slides were washed in PBS $1 \times$ containing $0.1 \%$ Tween $20(3 \times, 10 \mathrm{~min})$ under gentle agitation to remove unbound lectins and then were rinsed in PBS $1 \times(3 \times, 3 \mathrm{~min})$ and in ultrapure $\mathrm{H}_{2} \mathrm{O}$ to remove salt. Slides were finally dried under argon and scanned (Labomix Innoscan 710, red laser, excitation wavelength $635 \mathrm{~nm}$ ).

$K_{d}$ Evaluation. Interaction assays were performed using the same protocol. Immobilized glycoconjugates were probed with $25 \mu \mathrm{g} / \mathrm{mL}$ to $50 \mathrm{ng} / \mathrm{mL}$ Alexa Fluor 647-labeled H. pomatia agglutinin lectin (HPA) to ensure an excess of lectin.

Competition Assay Protocol and $I C_{50}$ Evaluation. In protein low-bind eppendorf tubes, the concentration range of commercial GalNAc (50 $\mathrm{mM}$ to $1 \mu \mathrm{M})$ was prepared in a solution containing Alexa Fluor 647-labeled $H$. pomatia agglutinin lectin (HPA) $(1 \mathrm{ng} / \mathrm{mL})$ in PBS $1 \times$ containing $0.1 \%$ BSA. Samples were incubated for $1 \mathrm{~h}$ at $37^{\circ} \mathrm{C}$ under agitation. Printed slides were disposed into 16-well masks. Fields containing immobilized glycoconjugates were probed with the previously incubated solutions containing GalNAc/ HPA lectin. Slides were incubated for $1 \mathrm{~h}$ at $37^{\circ} \mathrm{C}$ under slow agitation. Slides were washed in PBS $1 \times$ containing $0.1 \%$ Tween $20(3 \times, 10 \mathrm{~min})$ under gentle agitation to remove unbound lectins and the competitor and then were rinsed in PBS $1 \times(3 \times, 3 \mathrm{~min})$ and in ultrapure $\mathrm{H}_{2} \mathrm{O}$ to remove salt. Slides were finally dried under argon and scanned.

Data Analyses. Scans were analyzed with Mapix. To analyze the entire range of spots including inhomogeneous ones, a fixed diameter was imposed $(200 \mu \mathrm{m})$, equivalent to the minimal diameter observed on the slide. Data were treated with Excel and GraphPad Prism 6. To evaluate the interaction and approximatively determine $K_{\mathrm{d}}$ values, a hyperbole model was used to fit the data, with $Y$ being the mean fluorescence and $X$ being the concentration in lectin. To obtain an accurate value of $K_{\mathrm{d}}$, a linear regression $Y=A X+B$ was plotted (see equation below) and $K_{\mathrm{d}}$ was determined. To evaluate $\mathrm{IC}_{50}$ values, a sigmoidal model (4PL model), which is a variable slope model, was used to fit the data, with $Y$ being the mean fluorescence and $X$ being the $\log$ of the concentration in competitor introduced.

$$
\frac{[\text { lectin }]}{\text { fluorescence }}=[\text { lectin }] \frac{1}{\text { fluorescence }_{\text {max }}}+\frac{K_{\mathrm{d}}}{\text { fluorescence }_{\text {max }}}
$$

\section{ASSOCIATED CONTENT}

\section{Supporting Information}

The Supporting Information is available free of charge on the ACS Publications website at DOI: 10.1021/acsomega.8b01526.

General synthetic procedures; compound characterization (RP-HPLC, ESI-TOF, and ${ }^{1} \mathrm{H}$ NMR), experimental procedure for determination of dissociation constants $\left(K_{\mathrm{d}}\right)$ by the microarray, $\mathrm{IC}_{50}$ evaluation by the microarray and enzyme-linked lectin assays (PDF)

\section{AUTHOR INFORMATION}

\section{Corresponding Authors}

*E-mail: david.goyard@univ-grenoble-alpes.fr (D.G.).

*E-mail: olivier.renaudet@univ-grenoble-alpes.fr (O.R.).

ORCID

Olivier Renaudet: 0000-0003-4963-3848

Notes

The authors declare no competing financial interest.

\section{ACKNOWLEDGMENTS}

This work was supported by CNRS, Université Grenoble Alpes, the "Communauté d'agglomération Grenoble-Alpes Métropole" (Nanobio program), the French ANR project Glyco@Alps (ANR-15-IDEX-02) and Labex ARCANE (ANR11-LABX-003). O.R. acknowledges the European Research Council Consolidator Grant "LEGO" (647938) for D.G. and E.L.

\section{REFERENCES}

(1) Cecioni, S.; Imberty, A.; Vidal, S. Glycomimetics versus Multivalent Glycoconjugates for the Design of High Affinity Lectin Ligands. Chem. Rev. 2015, 115, 525-561.

(2) Galan, M. C.; Dumy, P.; Renaudet, O. Multivalent Glyco(Cyclo)Peptides. Chem. Soc. Rev. 2013, 42, 4599-4612.

(3) Bernardi, A.; Jiménez-Barbero, J.; Casnati, A.; Castro, C. D.; Darbre, T.; Fieschi, F.; Finne, J.; Funken, H.; Jaeger, K.-E.; Lahmann, 
M.; et al. Multivalent Glycoconjugates as Anti-Pathogenic Agents. Chem. Soc. Rev. 2013, 42, 4709-4727.

(4) Lee, Y. C.; Lee, R. T. Carbohydrate-Protein Interactions: Basis of Glycobiology. Acc. Chem. Res. 1995, 28, 321-327.

(5) Mammen, M.; Choi, S.-K.; Whitesides, G. M. Polyvalent Interactions in Biological Systems: Implications for Design and Use of Multivalent Ligands and Inhibitors. Angew. Chem., Int. Ed. 1998, 37, $2755-2794$.

(6) Lundquist, J. J.; Toone, E. J. The Cluster Glycoside Effect. Chem. Rev. 2002, 102, 555-578.

(7) Ortiz Mellet, C.; Nierengarten, J.-F.; Garcia Fernandez, J. M. Multivalency as an Action Principle in Multimodal Lectin Recognition and Glycosidase Inhibition: A Paradigm Shift Driven by CarbonBased Glyconanomaterials. J. Mater. Chem. B 2017, 6428-6436.

(8) Müller, C.; Despras, G.; Lindhorst, T. K. Organizing Multivalency in Carbohydrate Recognition. Chem. Soc. Rev. 2016, 45, 3275-3302.

(9) Bryan, M. C.; Fazio, F.; Lee, H. K.; Huang, C. Y.; Chang, A.; Best, M. D.; Calarese, D. A.; Blixt, O.; Paulson, J. C.; Burton, D.; et al. Covalent Display of Oligosaccharide Arrays in Microtiter Plates. J. Am. Chem. Soc. 2004, 126, 8640-8641.

(10) Disney, M. D.; Seeberger, P. H. The Use of Carbohydrate Microarrays to Study Carbohydrate-Cell Interactions and to Detect Pathogens. Chem. Biol. 2004, 11, 1701-1707.

(11) Biskup, M. B.; Müller, J. U.; Weingart, R.; Schmidt, R. R. New Methods for the Generation of Carbohydrate Arrays on Glass Slides and Their Evaluation. ChemBioChem 2005, 6, 1007-1015.

(12) Ortiz Mellet, C.; García Fernández, J. M. Carbohydrate Microarrays. ChemBioChem 2002, 3, 819-822.

(13) Houseman, B. T.; Mrksich, M. Carbohydrate Arrays for the Evaluation of Protein Binding and Enzymatic Modification. Chem. Biol. 2002, 9, 443-454.

(14) Dyukova, V. I.; Shilova, N. V.; Galanina, O. E.; Rubina, A. Y.; Bovin, N. V. Design of Carbohydrate Multiarrays. Biochim. Biophys. Acta, Gen. Subj. 2006, 1760, 603-609.

(15) Dendane, N.; Hoang, A.; Renaudet, O.; Vinet, F.; Dumy, P.; Defrancq, E. Surface Patterning of (Bio)Molecules onto the Inner Wall of Fused-Silica Capillary Tubes. Lab Chip 2008, 8, 2161-2163.

(16) Park, S.; Lee, M. R.; Shin, I. Fabrication of Carbohydrate Chips and Their Use to Probe Protein-Carbohydrate Interactions. Nat. Protoc. 2007, 2, 2747-2758.

(17) Hyun, J. Y.; Pai, J.; Shin, I. The Glycan Microarray Story from Construction to Applications. Acc. Chem. Res. 2017, 50, 1069-1078.

(18) Laurent, N.; Voglmeir, J.; Flitsch, S. L. Glycoarrays-Tools for Determining Protein-Carbohydrate Interactions and Glycoenzyme Specificity. Chem. Commun. 2008, 4400-4412.

(19) Sulak, O.; Lameignère, E.; Wimmerova, M.; Imberty, A. Specificity and Affinity Studies in Lectin/Carbohydrate Interactions. In Carbohydrate Chemistry; The Royal Society of Chemistry, 2009; Vol. 35, pp 357-372.

(20) Blixt, O.; Head, S.; Mondala, T.; Scanlan, C.; Huflejt, M. E.; Alvarez, R.; Bryan, M. C.; Fazio, F.; Calarese, D.; Stevens, J.; et al. Printed Covalent Glycan Array for Ligand Profiling of Diverse Glycan Binding Proteins. Proc. Natl. Acad. Sci. U.S.A. 2004, 101, 1703317038 .

(21) Branderhorst, H. M.; Ruijtenbeek, R.; Liskamp, R. M. J.; Pieters, R. J. Multivalent Carbohydrate Recognition on a Glycodendrimer-Functionalized Flow-through Chip. ChemBioChem 2008, 9, 1836-1844.

(22) Parera Pera, N.; Branderhorst, H. M.; Kooij, R.; Maierhofer, C.; Van Der Kaaden, M.; Liskamp, R. M. J.; Wittmann, V.; Ruijtenbeek, R.; Pieters, R. J. Rapid Screening of Lectins for Multivalency Effects with a Glycodendrimer Microarray. ChemBioChem 2010, 11, 18961904.

(23) Chevolot, Y.; Bouillon, C.; Vidal, S.; Morvan, F.; Meyer, A.; Cloarec, J. P.; Jochum, A.; Praly, J. P.; Vasseur, J. J.; Souteyrand, E. DNA-Based Carbohydrate Biochips: A Platform for Surface GlycoEngineering. Angew. Chem., Int. Ed. 2007, 46, 2398-2402.
(24) Goudot, A.; Pourceau, G.; Meyer, A.; Gehin, T.; Vidal, S.; Vasseur, J. J.; Morvan, F.; Souteyrand, E.; Chevolot, Y. Quantitative Analysis (Kd and IC50) of Glycoconjugates Interactions with a Bacterial Lectin on a Carbohydrate Microarray with DNA Direct Immobilization (DDI). Biosens. Bioelectron. 2013, 40, 153-160.

(25) Angeli, A.; Li, M.; Dupin, L.; Vergoten, G.; Noël, M.; Madaoui, M.; Wang, S.; Meyer, A.; Géhin, T.; Vidal, S.; et al. Design and Synthesis of Galactosylated Bifurcated Ligands with Nanomolar Affinity for Lectin LecA from Pseudomonas Aeruginosa. ChemBioChem 2017, 18, 1036-1047.

(26) Wang, S.; Dupin, L.; Noël, M.; Carroux, C. J.; Renaud, L.; Géhin, T.; Meyer, A.; Souteyrand, E.; Vasseur, J. J.; Vergoten, G.; et al. Toward the Rational Design of Galactosylated Glycoclusters That Target Pseudomonas Aeruginosa Lectin A (LecA): Influence of Linker Arms That Lead to Low-Nanomolar Multivalent Ligands. Chem. - Eur. J. 2016, 22, 11785-11794.

(27) Sanchez, J. F.; Lescar, J.; Chazalet, V.; Audfray, A.; Gagnon, J.; Alvarez, R.; Breton, C.; Imberty, A.; Mitchell, E. P. Biochemical and Structural Analysis of Helix pomatia Agglutinin: A Hexameric Lectin with a Novel Fold. J. Biol. Chem. 2006, 281, 20171-20180.

(28) Hoang, A.; Laigre, E.; Goyard, D.; Defrancq, E.; Vinet, F.; Dumy, P.; Renaudet, O. An Oxime-Based Glycocluster Microarray. Org. Biomol. Chem. 2017, 15, 5135-5139.

(29) Berthet, N.; Thomas, B.; Bossu, I.; Dufour, E.; Gillon, E.; Garcia, J.; Spinelli, N.; Imberty, A.; Dumy, P.; Renaudet, O. High Affinity Glycodendrimers for the Lectin LecB from Pseudomonas Aeruginosa. Bioconjugate Chem. 2013, 24, 1598-1611.

(30) Pifferi, C.; Goyard, D.; Gillon, E.; Imberty, A.; Renaudet, O. Synthesis of Mannosylated Glycodendrimers and Evaluation against BC2L-A Lectin from Burkholderia Cenocepacia. ChemPlusChem 2017, 82, 390-398.

(31) Thomas, B.; Pifferi, C.; Daskhan, G. C.; Fiore, M.; Berthet, N.; Renaudet, O. Divergent and Convergent Synthesis of GalNAcConjugated Dendrimers Using Dual Orthogonal Ligations. Org. Biomol. Chem. 2015, 13, 11529-11538.

(32) Miller, N.; Williams, G. M.; Brimble, M. A. Synthesis of Fish Antifreeze Neoglycopeptides Using Mcrowave-Assisted "Click Chemistry". Org. Lett. 2010, 12, 1375-1376.

(33) Loka, R. S.; Sadek, C. M.; Romaniuk, N. A.; Cairo, C. W. Conjugation of Synthetic N-Acetyl-Lactosamine to Azide-Containing Proteins Using the Staudinger Ligation. Bioconjugate Chem. 2010, 21, 1842-1849.

(34) Wilczewski, M.; Van der Heyden, A.; Renaudet, O.; Dumy, P.; Coche-Guérente, L.; Labbé, P. Promotion of Sugar-Lectin Recognition through the Multiple Sugar Presentation Offered by Regioselectively Addressable Functionalized Templates (RAFT): A QCM-D and SPR Study. Org. Biomol. Chem. 2008, 6, 1114-1122.

(35) Dupin, L.; Zuttion, F.; Géhin, T.; Meyer, A.; Phaner-Goutorbe, M.; Vasseur, J. J.; Souteyrand, E.; Morvan, F.; Chevolot, Y. Effects of the Surface Densities of Glycoclusters on the Determination of Their IC50 and Kd Value Determination by Using a Microarray. ChemBioChem 2015, 16, 2329-2336.

(36) Kuno, A.; Uchiyama, N.; Koseki-Kuno, S.; Ebe, Y.; Takashima, S.; Yamada, M.; Hirabayashi, J. Evanescent-Field FluorescenceAssisted Lectin Microarray: A New Strategy for Glycan Profiling. Nat. Methods 2005, 2, 851-856.

(37) Park, S.; Shin, I. Carbohydrate Microarrays for Assaying Galactosyltransferase Activity. Org. Lett. 2007, 9, 1675-1678.

(38) Godula, K.; Bertozzi, C. R. Density Variant Glycan Microarray for Evaluating Cross-Linking of Mucin-like Glycoconjugates by Lectins. J. Am. Chem. Soc. 2012, 134, 15732-15742.

(39) Liang, C. H.; Wang, S. K.; Lin, C. W.; Wang, C. C.; Wong, C. $\mathrm{H}$.; Wu, C. Y. Effects of Neighboring Glycans on AntibodyCarbohydrate Interaction. Angew. Chem., Int. Ed. 2011, 50, 16081612. 